MATEC Web of Conferences 11,01042 (2014)

DOI: $10.1051 /$ matecconf / 20141101042

(C) Owned by the authors, published by EDP Sciences, 2014

\title{
Development of an accelerated test for Internal Sulfate Attack study
}

\author{
Nacim KHELIL ${ }^{1}$, Jean-Emmanuel AUBERT ${ }^{1}$, Gilles ESCADEILLAS $^{1}$ \\ ${ }^{1}$ Université de Toulouse; UPS, INSA; LMDC (Laboratoire Matériaux et Durabilité des Constructions); Toulouse, France
}

\begin{abstract}
Internal Sulfate Attack (ISA) is a pathology that occurs under certain conditions in concrete having undergone heating above $70^{\circ} \mathrm{C}$ at early age (through heating in pre-casting industry or due to hydration in large concrete parts). This reaction deemed very slow, numerous methods to speed up reactions leading to delayed ettringite formation have been developed. These methods are all based on the material damage. Another type of test is currently under development. It is based on rehabilitation techniques such as electrochemical chloride extraction (ECE) in order to accelerate the leaching of alkalis that could be one of the triggers of the pathology. The study presented in this paper focused on concrete specimens prepared from cement (CEM I $52.5 \mathrm{~N}$ ) enriched with $\mathrm{Na}_{2} \mathrm{SO}_{4}$. These concretes have undergone a heat treatment typical of those used in precast plants (up to 24 hours with a maximum temperature of $80^{\circ} \mathrm{C}$ ). Various paths were explored for the development of the accelerated test. The first results showed that it was necessary to use a removable titanium anode ruthenium anode instead of stainless steel embedded in the concrete. Then tests with de-ionized water as the solute to the cathode did not accelerate the onset of expansions. The experiment has been modified and potassium carbonate was added to the solution. This modification didn't show any significant improvement, and other experiments are being carried out to explain this result.
\end{abstract}

\section{Introduction}

Internal Sulfate Attack (ISA) is a relatively new pathology (appeared in the early 1980s in Europe and North America) [12] compared to other pathologies affecting the concrete, such as alkali-aggregate reaction or even external sulphate attack, which are known from the middle or even the beginning of the 20th century.

ISA can be defined as the late formation of expansive ettringite in a cementitious material already hardened without external supply of sulfates. That phenomenon leads to the development of deleterious expansions [1], which results in the cracking of the material and the decrease of the mechanical properties and durability provided that the temperature within the concrete exceeds a certain limit of about $70{ }^{\circ} \mathrm{C}$ [2] [9], allowing the remobilization of sulphates originally present in the cement matrix. The ISA is commonly encountered in the case of precast concrete pieces thermally treated; however, it can also appear in large concrete pieces within which the temperature exceeded $70{ }^{\circ} \mathrm{C}$ during their thermal history.

Numerous papers aiming to understand the reactional phenomena have been published on the ISA for several decades with a marked acceleration in recent years. However, the ISA is characterized by a very slow reaction kinetics and therefore it is difficult to study it in laboratory. A paper from Leklou et al. [8] showed that the leaching of alkali could be one of the triggers of this reaction. Indeed, alkalis have the singularity to increase the solubility limit of ettringite. Therefore, their leaching might help reduce the solubility of ettringite and thus allow its late appearance. Based on this assumption, we believe it would be possible to speed up the onset of this pathology by applying an electric current to the concrete in order to migrate alkalis faster. This paper focuses on the development of preliminary tests inspired by electrochemical rehabilitation treatments such as electrochemical chloride extraction [3][6], in order to accelerate the onset of the aforementioned pathology.

\section{Materials and processes}

\subsection{Materials}

$11 \times 22 \mathrm{~cm}$ cylindrical specimens of concrete were made using an ordinary Portland cement CEM I $52.5 \mathrm{~N}$. The chemical and mineralogical compositions of the cement used, are presented in Tables 1 and 2 respectively. To accelerate the development of ettringite, $3.1 \%$ (by mass of cement) of $\mathrm{Na}_{2} \mathrm{SO}_{4}$ were added to the concrete

This is an Open Access article distributed under the terms of the Creative Commons Attribution License 2.0, which permits unrestricted use, distribution, and reproduction in any medium, provided the original work is properly cited. 
designed from the above-mentioned cement. From now on, this cement is referred to as cement "BS", "B" referring to the cement used for these tests and "S" referring to the sulfates enrichment. The aggregates used in the concrete are of siliceous nature, classified as nonreactive in relation to the Alkali-Silica Reaction (NF P $18-590)$. From this material, a concrete $(\mathrm{W} / \mathrm{C}=0.48)$ was produced in accordance with the composition recommended for concretes in the GranDuBé national project [7] and presented in Table 3.

Table 1. Chemical composition of cement B.

\begin{tabular}{|c|c|}
\hline Cement B & $\begin{array}{c}\text { Composition } \\
\text { (\%) }\end{array}$ \\
\hline $\mathrm{SiO}_{2}$ & 19.8 \\
\hline $\mathrm{Al}_{2} \mathrm{O}_{3}$ & 5.3 \\
\hline $\mathrm{Fe}_{2} \mathrm{O}_{3}$ & 2.4 \\
\hline $\mathrm{CaO}$ & 64.2 \\
\hline $\mathrm{MgO}$ & 1.8 \\
\hline $\mathrm{SO}_{3}$ & 3.1 \\
\hline $\mathrm{K}_{2} \mathrm{O}$ & 0.5 \\
\hline $\mathrm{Na}_{2} \mathrm{O}$ & 0.2 \\
\hline
\end{tabular}

Table 2. Mineralogical composition of cement B.

\begin{tabular}{|c|c|}
\hline Cement B & Content (\%) \\
\hline $\mathrm{C} 3 \mathrm{~S}$ & 62.3 \\
\hline $\mathrm{C} 2 \mathrm{~S}$ & 9.8 \\
\hline $\mathrm{C} 3 \mathrm{~A}$ & 10 \\
\hline $\mathrm{C} 4 \mathrm{AF}$ & 7.4 \\
\hline
\end{tabular}

Table 3. Composition of studied concretes [7].

\begin{tabular}{|c|c|}
\hline Component & Quantity (Kg) \\
\hline Cement & 410 \\
\hline Water & 197 \\
\hline Sand 0/0.315 & 93.5 \\
\hline Sand 0.315/1 & 174 \\
\hline Sand 1/4 & 184 \\
\hline Sand 2/4 & 196 \\
\hline Gravel 4/8 & 188 \\
\hline Gravel 8/12.5 & 878 \\
\hline
\end{tabular}

\subsection{Processes}

\subsubsection{Thermal treatment}

After putting the concrete in the cylindrical molds, the specimens have been heat treated according to the protocol shown in Figure 1. This heat treatment of $24 \mathrm{~h}$ is supposed to represent the type of treatment applied in the precast industry of concrete elements. The thermal cycle is divided into four distinct phases:

- Pre-treatment at $20^{\circ} \mathrm{C}$ for 1 hour,

- Temperature rise from 20 to $80{ }^{\circ} \mathrm{C}$ over $3 \mathrm{~h}$ phase,

- Plateau phase of $80{ }^{\circ} \mathrm{C}$ temperature held during $10 \mathrm{~h}$, - Cooling phase for $10 \mathrm{~h}$.

Put in a programmable oven, the specimens are coated with a layer of water and sealed to prevent fluid exchange with the outer environment (oven) during heating. The specimens were also weighed before and after oven drying to verify the absence of weight loss (results not presented in the present work). To make sure that the theoretical thermal cycle is respected, the temperature has been verified through thermocouples placed in the oven and the core of the concrete specimens to measure their response to the treatment. The treatment over, the samples were then stored at $20{ }^{\circ} \mathrm{C}$ and immersed in deionized water.

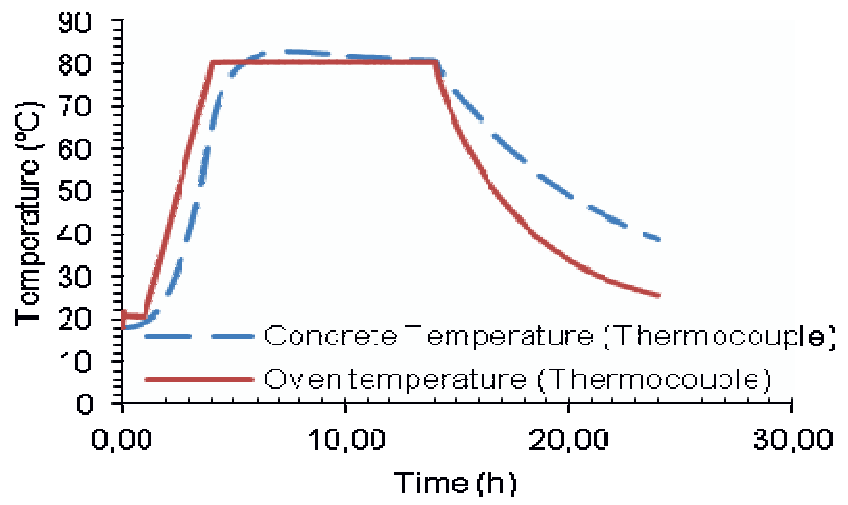

Fig. 1. 24h thermal treatment applied to the concrete specimens.

\subsubsection{Experimental set-up}

Ettringite formation being a very-long-latency-period reaction, it is quite difficult to study the phenomenon adequately in laboratory. One hypothesis, derived from previous studies regarding the pathology [8], is that the delayed ettringite formation is governed by alkali leaching from the pore solution to the external environment (diffusion). Thus, we believe that the application of an electric current to move these ions more rapidly by migration would accelerate the occurrence of ISA. To assess it, two types of experimental set-ups have been developed on the basis of rehabilitation methods such as electrochemical chloride extraction (ECE) or even realkalisation. of:

The first experimental set-up (Figure 2 left) consists 
- a $11 \times 22 \mathrm{~cm}$ cylindrical concrete sample with an internal stainless steel bar (AN) $(\Phi=10 \mathrm{~mm})$ dipped on $17 \mathrm{~cm}$ into the concrete. To reduce the proportion of sample to be studied, only a portion of $10 \mathrm{~cm}$ of steel is actually electrically active (i.e. non-insulated). The internal stainless steel bar is an anode and is connected to the $(+)$ terminal of the circuit.

- an outer titanium mesh placed on the contour of the specimen is connected to the (-) terminal of the circuit, The specimen is kept during treatment in a container with de-ionized water.

The second experimental set-up (Figure 2 right) differs only slightly from the first one:

- a $11 \times 22 \mathrm{~cm}$ cylindrical concrete sample with an internal reservoir of $17 \mathrm{~cm}$ in length and $2 \mathrm{~cm}$ in diameter.

- a ruthenium titanium electrode (TR) $(\Phi=3 \mathrm{~mm})$ was introduced into the reservoir then connected to the $(+)$ terminal of the circuit. To reduce the proportion of the sample to be studied, only a portion of $10 \mathrm{~cm}$ of the electrode is actually electrically active i.e. not insulated. The reservoir is blocked by an aluminum foil to prevent evaporation of the conductive solution (water + lime $(\mathrm{Ca}$ $\left.(\mathrm{OH})_{2}\right)$ at different dosages).

- an outer titanium mesh is placed on the contour of the test piece and then connected to the (-) terminal of the circuit.

The specimen is kept during treatment in a container with deionized water or a solution of $\mathrm{K}_{2} \mathrm{CO}_{3}$.

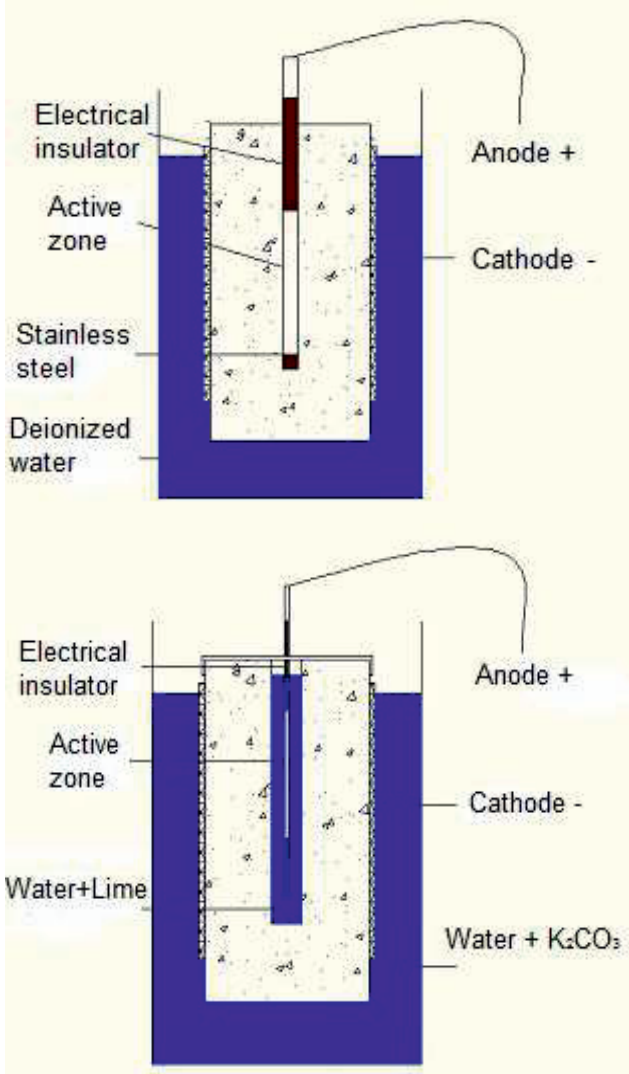

Fig. 2. Experimental set-ups EA and TR.
Table 4. Solutions and concentrations used for the accelerated tests.

\begin{tabular}{|c|c|c|c|}
\hline Specimens & $\begin{array}{c}\text { Dosage } \\
\mathbf{C a}(\mathbf{O H})_{2} \\
(\mathbf{M o l} / \mathbf{l})\end{array}$ & $\begin{array}{c}\text { Solution de } \\
\text { conservation }\end{array}$ & $\begin{array}{c}\text { Concentration } \\
\mathbf{K}_{\mathbf{2}} \mathbf{C O}_{\mathbf{3}}(\mathbf{M o l} / \mathbf{l})\end{array}$ \\
\hline BS AN & - & De-ionized water & - \\
\hline \multirow{2}{*}{ BS TR } & 0.25 & De-ionized water & - \\
\cline { 2 - 4 } & 1 & $\begin{array}{c}\text { De-ionized water } \\
+\mathrm{K}_{2} \mathrm{CO}_{3}\end{array}$ & 0.5 \\
\hline
\end{tabular}

In the case of the embedded anode (AN), we conducted preliminary tests with intensities of 1 and $5 \mathrm{~A} / \mathrm{m}^{2}$ (reported to the anode surface) that correspond to conventional current intensity levels for ECE treatments [5]. Two treatment durations were tested: 7 and 28 days.

In the case of the removable Titanium Ruthenium anodes (TR), we sought to increase the effectiveness of treatment and make it as short as possible. Therefore, we have significantly increased current density. Table 5 shows the different parameters used for the electrochemical treatment.

Table 5. Electrochemical treatment TR (durations and intensities).

\begin{tabular}{|c|c|c|c|c|}
\hline Specimens & $\begin{array}{l}\text { BS- } \\
\text { TR1 }\end{array}$ & $\begin{array}{l}\text { BS- } \\
\text { TR2 }\end{array}$ & $\begin{array}{l}\text { BS- } \\
\text { TR3 }\end{array}$ & $\begin{array}{l}\text { BS- } \\
\text { TR4 }\end{array}$ \\
\hline Intensity (mA) & 25 & 25 & 50 & 50 \\
\hline Duration (days) & 2 & 7 & 2 & 7 \\
\hline Surface $\left(\mathrm{m}^{2}\right)$ & $\begin{array}{l}9.42 \mathrm{x} \\
10^{-4}\end{array}$ & $\begin{array}{c}9.42 \mathrm{x} \\
10^{-4}\end{array}$ & $\begin{array}{c}9.42 \mathrm{x} \\
10^{-4}\end{array}$ & $\begin{array}{c}9.42 \mathrm{x} \\
10^{-4}\end{array}$ \\
\hline $\begin{array}{c}\text { Current density } \\
\left(\mathrm{A} / \mathbf{m}^{2}\right)\end{array}$ & 27 & 27 & 53 & 53 \\
\hline $\begin{array}{c}\text { Total charge } \\
\left(\mathbf{A h} / \mathbf{m}^{2}\right)\end{array}$ & 1274 & 4459 & 8917 & 2548 \\
\hline
\end{tabular}

\subsubsection{Measurements}

The expansions monitoring of the tested specimens was performed using a 1-micron-precision detachable extensometer. Each point of the graphs represents the average of three measurements on each specimen expansions. Reference value of expansions (start of measurement) value was taken 7 days.

\section{Results and discussions}

\subsection{Expansions of BS specimens}

Figure 3 shows the expansions measured on specimens BS. Two phases can be distinguished in the expansions kinetics:

- a phase of slow expansion: the first phase lasts about 350 days, and has a quasi-linear profile. We note at this stage that the threshold of $0.04 \%$ (threshold to be reached after a year for a concrete formula is considered reactive [4][10] is exceeded at about 150 days. 
- an acceleration phase: this second phase is characterized by a marked acceleration starting from $0.1 \%$ expansions.

These results show that the kinetics of expansion of the studied concrete remains slow despite the addition of $\mathrm{Na}_{2} \mathrm{SO}_{4}$ to speed the phenomena up. We can also note in this regard the significant differences with the mortars studied by [8] which are prepared from the same cement mixture and have undergone the same heat treatment. In the case of mortars, the slow expansion phase is much shorter than that of concrete (100 days for the mortars against 350 days for the concrete) and is characterized by much lower expansions in the case of the mortar compared to concrete.

The slow expansion observed for these concretes $\mathrm{Na}_{2} \mathrm{SO}_{4}$-enriched confirms the need to develop experimental methods to accelerate the phenomena leading to the onset of ISA.

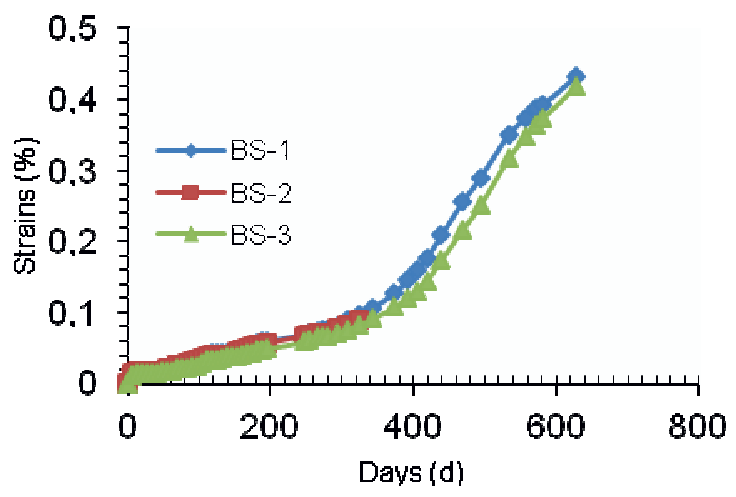

Fig. 3. Expansion of specimens BS.

\subsection{Electrochemical treatments with embedded anode (EA)}

In the case of the treatment of samples with embedded stainless steel, we noticed the appearance of longitudinal cracks on the specimens that have undergone long-term treatment (28 days) and high intensity $\left(5 \mathrm{~A} / \mathrm{m}^{2}\right)$. A splitting of the specimens showed corrosion of the internal stainless steel bars. However, for the other treated samples ( $1 \mathrm{~A} / \mathrm{m}^{2}$ for 7 and 28 days), the splitting also showed corrosion of stainless steel but without creating cracks.

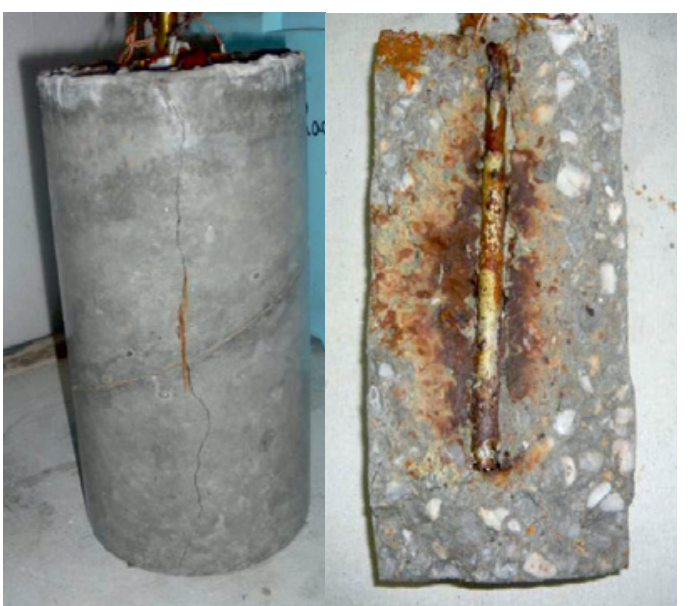

Fig. 4. Cracks on the material and corrosion of the stainless steel bar (28 day-treatment at $5 \mathrm{~A} / \mathrm{m}^{2}$ ).

As seen on the split sample, a front of iron oxides formed around the "active" area of steel i.e. subjected to electric current. These preliminary results showed, therefore, that it was not possible to use a stainless steel anode embedded in the concrete as this one gets corroded. This is unfortunate because on an experimental point of view, this test was the easiest to implement. To rule out this expansion problem due to the anode corrosion, we were forced to change our experimental process as presented in Section 2.2.2.

\subsection{Electrochemical treatments with Titanium Ruthenium removable anode (TR)}

\subsubsection{Case of de-ionized water solution}

Figure 5 shows the expansions of BS-cement-based specimens which underwent an electric current, and the control specimens (BS-4 and BS-5 with no treatment).

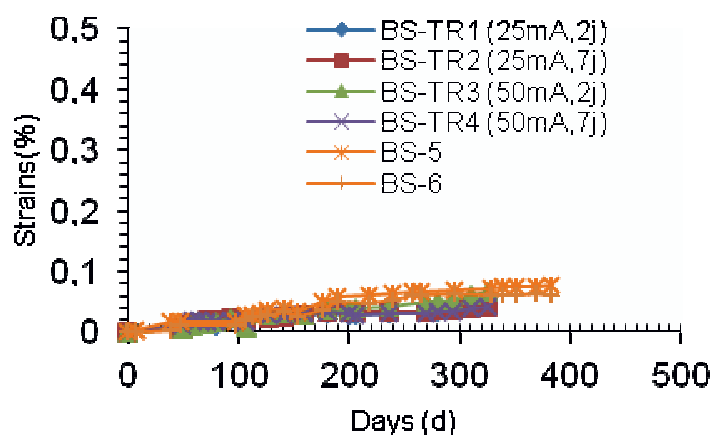

Fig. 5. Expansions of specimens BS-TR (de-ionized water).

The results show no acceleration for the expansions due to the application of the electrochemical treatment. One hypothesis advanced to explain this result is that under electrical power, two electrolysis reactions occur at the electrodes:

- On the one hand the anodic reaction:

$2 \mathrm{OH}^{-} \rightarrow 1 / 2 \mathrm{O}_{2}+\mathrm{H}_{2} \mathrm{O}+2 \mathrm{e}^{-}$ 
Which occurs at the Titanium Ruthenium anode in the reservoir containing de-ionized water $+\mathrm{Ca}(\mathrm{OH})_{2}$. The choice of lime as a solute has also been made to provide hydroxide ions $\mathrm{OH}^{-}$to the solution in order to consumed during the reaction.

- On the other hand, the cathodic reaction:

$$
2 \mathrm{H}_{2} \mathrm{O}+2 \mathrm{e}^{-} \rightarrow \mathrm{H}_{2}+\mathrm{OH}^{-}
$$

During this reaction (at the titanium mesh), there is a production of hydroxide ions in the solution. These hydroxide ions are the only negative species in the solution and they have a very high mobility $\left(20.50 \times 10^{-}\right.$ $\left.{ }^{4} \mathrm{~cm}^{2} /(\mathrm{vs})\right)$. Thus, to meet the electroneutrality of the solution, they will migrate to the material very quickly. These ions thus within the pore solution, contribute the $\mathrm{pH}$ increase beyond the domain of stability of ettringite (9-13 according to authors [11]) and thus inhibit any formation.

To avoid this phenomenon, one should enrich the outer concrete solution with soluble salts capable of providing anions other than $\mathrm{OH}^{-}$. We chose to use carbonates as anions that could contribute more to lower the $\mathrm{pH}$ in the concrete and therefore might lead to a faster precipitation of ettringite. In order to monitor the leaching of the major alkali in our mixtures (sodium), we used potassium carbonate.

\subsubsection{Case of $\mathrm{K}_{2} \mathrm{CO}_{3}$ solution}

Treatment with de-ionized water being ineffective, potassium carbonate $\mathrm{K}_{2} \mathrm{CO}_{3}(0.5 \mathrm{~N})$ was added to the solution. The addition of this solute has two assets as mentioned earlier:

- the solution contains a concentration of $\mathrm{CO}_{3}{ }^{2-}$ anions $>>\mathrm{OH}^{-}$(which only forms as the cathodic reaction goes), these will therefore be the main current conductor, minimizing hydroxides migration and therefore preventing the raise of the $\mathrm{pH}$ of the pore solution.

- the $\mathrm{CO}_{3}{ }^{2-}$ ions migrating under electric field, enter into the concrete and react with the portlandite $\mathrm{Ca}(\mathrm{OH})_{2}$ to form of calcite. Since the decrease in $\mathrm{pH}$ of the concrete influences the formation of ettringite, calcite formation should accelerate the appearance of RSI. As far as the couple (current, current duration) used during the treatment is concerned, it was decided to adopt the strongest treatment i.e. $50 \mathrm{~mA}$ for 7 days.

Figure 6 shows the strains measured on the samples treated by electric current in the case of adding $\mathrm{K}_{2} \mathrm{CO}_{3}$ into the solution and on two new control specimens (BSBS-6 and 7).

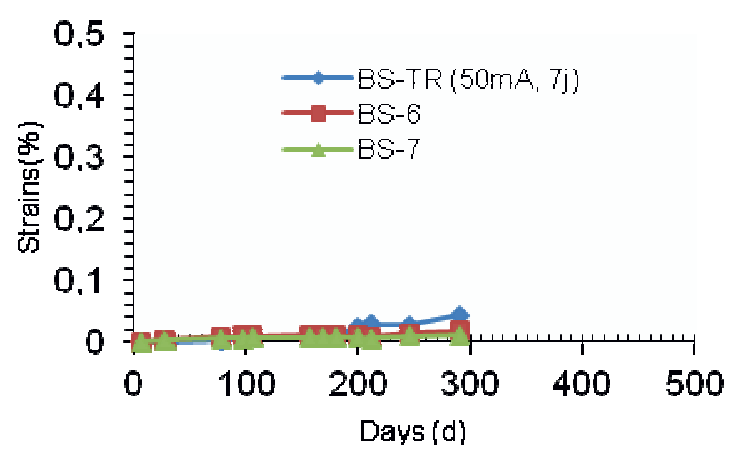

Fig. 6. Expansion of specimens BS-TR $\left(\mathrm{K}_{2} \mathrm{CO}_{3}\right.$ solution $)$.

The results do not show for the time being any marked acceleration in the expansion. A phenolphthalein test was performed on the treated specimen and showed that $\mathrm{CO}_{3}{ }^{2-}$ ions had not penetrated the concrete and did not allow the carbonation in depth.

We seek an explanation for this. It is possible that this test has led to a rapid precipitation of calcite on the edge of concrete. This could result in filling the porosity and thus reducing the efficiency of the electrochemical treatment. Studies on porosity of treated or untreated material are underway to assess these hypotheses.

\section{Conclusions}

The objective of the study presented in this paper was to find a way to accelerate the ISA of concrete having undergone high temperatures $\left(>70{ }^{\circ} \mathrm{C}\right)$ at young age. Assuming that the leaching of alkalis could act as a trigger in this pathology, we sought to accelerate the migration phenomenon by using an electrochemical treatment on concrete specimens to extract alkalis.

The results first showed that it was impossible to apply this treatment by embedding an anode made of stainless steel in the concrete. Indeed, in this case, and even for moderate electrochemical processes, the anode corrodes and the formation of iron oxides leads to expansions that crack the concrete specimens. So we were forced to change our experimental set-up using a removable ruthenium titanium anode placed in a reservoir in the core of the specimens. The first tests using deionized water as an external solution were not effective. The analysis of the results gave us assumptions about the reasons for this failure and so we changed our test by adding $\mathrm{K}_{2} \mathrm{CO}_{3}$ to the outer solution. Again, there was no onset of ISA acceleration as we had expected.

Trials are currently underway to explain this result.

The initial analyzes suggest that the carbonates didn't not enter the concrete as expected. Why? Is it because of a rapid carbonation on the periphery of the specimens that has limited the effectiveness of the electrochemical treatment? What about the alkalis originally present in the pore solution? Had the current an impact on their concentration and their location? Were we able to move the ions in the pore solution and if so how? If not, how to modify the electrochemical treatment to actually succeed in getting the alkalis out? And finally, is it going to have the desired effect on accelerating the precipitation of 
ettringite? These are questions that we will try to answer in future studies.

\section{References}

1. R. Barbarulo, Comportement des matériaux cimentaires: Action des sulfates et de la température, (ENS Cachan-Université Laval, 2002)

2. R. Barbarulo, H. Peycelona,S. Prené , J. Marchand, Cement and concrete research, 35, 125 (2005)

3. G. Bikul'chus, Chloride removal from reinforced concrete and relevant loss of strength, Protection of Metals, 41, 484 (2005)

4. X. Brunetaud, Etude de l'influence de différents paramètres et de leurs interactions sur la cinétique et l'amplitude de la réaction sulfatique interne au béton(École Centrale des Arts et Manufactures, École Centrale Paris, 2005)

5. C. Christodoulou, Electrochemical treatments of corroded reinforcement in concrete, 2nd International conference on Concrete Repair, Rehabilitation and Retrofitting, (CRC Press), 1, 799 (2008)

6. G. Fajardo, G. Escadeillas, G. Arliguie, Corrosion science, 48, 110 (2006)

7. GranDuBé. Grandeurs associées à la durabilité des bétons (Presses de l'école nationale des Ponts et Chaussées, ENPC, 2007)

8. N. Leklou, J-E. Aubert, G. Escadeillas, Materials and Structures, 42, 1369 (2009)

9. I. Odler, Y. Chen, Cement and Concrete Research, 25, 853 (1995)

10. N. Petrov, A. Tagnit-Hamou, ACI Materials Journal, 101, 442 (2004)

11. J. Stark, K. Bollmann, Delayed Ettringite Formation in Concrete, (Bauhaus-University 1998)

12. P. Tepponen, B. E. Eriksson, Nordic Concrete Research, 6, 199 (1987) 